\title{
Orbital Complications of Sinusitis
}

\author{
Pjerin Radovani, Dritan Vasili, Mirela Xhelili, Julian Dervishi \\ Department of Otorhinolaryngology-Ophthalmology, University Hospital Center of Tirana, Tirana, Albania
}

\begin{abstract}
Background: Despite the modern antibiotherapies applied in the practice of otorhinolaryngology, the orbital complications of sinusitis are still considered a serious threat to essential functions of the eye, including loss of vision, and at worst, life threatening symptoms.

Aims: The goal of this study is to consider and analyse patients who were treated for these complications in the last decade in our hospital, which is the only tertiary hospital in our country.
\end{abstract}

Study Design: Retrospective analysis of cases.

Methods: In our practice, cases treated in the hospital are rhinosinusitis cases where surgical intervention is necessary, or those with a suspicion of complications. Between the years 1999 and 2009 there were 177 cases, the clinical charts of which were reviewed. The cases that are omitted from this study are those involving soft tissues, bone, and intracranial complications. The diagnoses were determined based on anamnesis, anterior rhinoscopy, x-rays of the sinuses with the Water's projection or where there was a suspicion of a complication, and CT scans with coronal and axial projections. In all cases, intensive treatment was initiated with a combination of cefalosporines, aminoglycosides and Proetz manoeuvre. When an improvement in the conditions did not occur within 24-48 hours, we intervened with a surgical procedure, preferably the Lynch-Patterson external frontoethmoidectomy.

Results: In our study, we encountered 35 cases (19.8\%) of orbital complications with an average age of 25 (range: 3-75); Palpebral inflammatory oedema (15), orbital cellulitis (10), subperiosteal abscess (6), orbital abscess (3), and cavernous sinus thrombosis (1 patient). The average time that patients remained in hospital was 4.6 days; for those with orbital complications this was 7 days.

Conclusion: Orbital complications of sinusitis are considered to be severe pathologies. The appearance of oedema in the corner of the eye should be evaluated immediately and the means to exclude acute sinusitis should be taken under serious consideration. Early diagnosis and aggressive treatment are key to the reduction of these unwanted manifestations.

Key Words: Sinusitis, orbital complications of sinusitis, treatment

Received: 25.10 .2012

Accepted: 20.02 .2013

\section{Introduction}

The complications of sinusitis include lesions that affect the soft tissues, the surrounding bones, the orbit, and the intracranial area. However, they rarely occur in soft tissues, and are more often seen as orbital, bone and intracranial complications $(1,2)$. We preferred this arrangement due to the dominance of orbital complications vs. bone and intracranial complications.

The methods for the treatment of these complications today are often debated: conservative, surgical or combined. Surgical options include both endoscopic and open surgery. However, in the era of endoscopic surgery of the nose and paranasal sinuses, there are still no clear advantages of these techniques over open interventions. In some reports we observe the use of both techniques, while some cases use either, without any comment on the value of these techniques. Lengthy hospital stays are not often reported (3-5), but some studies have reported long recovery times and severe ophthalmologic problems $(4,5)$. In our series we will present the experience of conservative and surgical treatment in University Hospital Centre of Tirana, as the only tertiary hospital in our country.
The purpose of this article is to analyse treated cases of orbital complications of sinusitis admitted to our department in the last decade.

\section{Material and Methods}

We have based our study on a thorough review of hospital records between the years 1999 and 2009. We selected all sinusitis cases, comprising 177 patients. In our practice, the cases that are admitted to the hospital are rhinosinusitis cases that need surgical intervention, particularly ones where intense pain is experienced, in those with a suspicion of complications developing, and in cases of complicated acute sinusitis.

We did not take into account complications in soft tissues, bone, or intracranial areas, since they represented only one or two cases of the whole series.

The diagnoses were determined based on anamnesis, anterior rhinoscopy, $x$-rays of the paranasal sinuses in the Water's projection, and, in certain cases where there was a suspicion of complication, CT scans. In cases where there was a suspicion of complications, or when the clinical diagnosis was orbital complication, there was an immediate consultation 
with the ophthalmologist and a collaborative treatment approach was chosen. In fact, a lot of these cases were referred to us by the Department of Ophthalmology or private clinics.

In all cases, intensive treatment was initiated with a combination of cefalosporines, aminoglycosides, and a modified Proetz procedure in accordance with recent guidelines. When an improvement in the patient's condition did not occur within 24-48 hours, we intervened with surgical procedures, preferably the external frontoethmoidectomy in combination with the Lynch-Patterson technique, because this allowed a wide opening, good drainage and clear entry to the nasal cavity. In two cases with one-sided pansinusitis, the Caldwell-Luc intervention was used, approaching the sinuses externally. When the imaging produced a clear view of the intraorbital complication, or if the patient experienced problems with vision, the intervention was applied within the first 24 hours. In this analysis of clinical material, we took into account age, gender, conservative treatment vs. surgical intervention and the average time of hospital stay.

\section{Results}

From this study of 177 cases there were 35 cases with orbital complications, which were further analysed. The youngest case encountered in the series was a 3 year old child, while the oldest was a 75 year old. Cases affecting younger patients dominated the series. The average age was 25.3 , which was an average similar to that reported by many other series. The average time that patients stayed in hospital was 4.6 days, while for those with orbital complications it was 7 days.

Orbital complications of sinusitis were classified primarily by Hubert in 1937, but it was Chandler who categorised them in 1970 , followed by later modifications by others $(6,7,8)$. The classifications of Chandler and Moloney remain the most commonly used to date $(8,9)$. Modifications were made in relation to CT-scan and MRI findings. We have referred to Chandler's classification; however, in Table 1 both classifications were included. The difference between the two systems only appears in the palpebral region.

In our study, we encountered 35 cases (19.8\%) with orbital complications. The cases and treatments based on Chandler's classification are found in Table 2.

The case of cavernous sinus thrombosis presented as pansinusitis of the left side and received ambulatory medical

Table 1. The most commonly accepted orbital classifications of sinuses

\begin{tabular}{|lll|}
\hline Group & Chandler & Moloney \\
\hline First & Inflammatory oedema & Preseptal cellulitis \\
Second & Orbital cellulitis & Subperiosteal abscess \\
Third & Subperiosteal abscess & Orbital cellulitis \\
Fourth & Orbital abscess & Orbital abscess \\
Fifth & Cavernous sinus & Cavernous sinus \\
& thrombosis & thrombosis \\
\hline
\end{tabular}

treatment for 10 days. The patient was admitted to the ophthalmology department, but was transferred to the hospital after two days. The patient had lost vision due to an orbital abscess, so we performed a complete opening of the left side of the sinuses. All other cases recovered without any functional problems.

\section{Discussion}

Even though the occurrences are significantly lower than decades ago, complications of sinusitis, whether acute or chronic, continue to appear despite progresses in therapy that have been achieved in recent years. The topographic anatomy of the orbit, which shows intimate relations with paranasal sinuses, provides a convincing explanation to these events. The Lamina Papyracea, which divides the orbit from the nasal space, is a thin layer of bone. Inside it are multiple thin blood vessels, which allow the spread of aggressive infection in the orbit. Inside the orbital vessels is where the palpebral vessels and those of the centre of the face drain and travel parallel with the lamina papyracea toward the sinus cavernosus. None of these vessels contain valves; therefore, there is an accelerated spread of infection. The periorbita is a strong barrier to infection and provides clinicians with time before they are faced with serious complications.

In our series, just as in many others, male patients dominated female patients with a ratio of 2 to 1 . The question of why this happens has been repeatedly asked through the years, but there is still no definite explanation for this observation. It is believed that the female immune system is more proficient than that of males (8). Also, the higher number of occurrences of these complications in young patients is another observation noted not only here, but by many other researchers (7-10). This study also found a dominance of orbital complications involving bone (1 case) and intracranial complications ( 2 cases). This observation is imperative to a better understanding of orbital complications from both clinical and imaging points of view. Due to the acceptance of several classifications, the nomencla-

Table 2. Classifications of our cases and the corresponding treatment

\begin{tabular}{|c|c|c|}
\hline $\begin{array}{l}\text { Complication } \\
\text { according Chandler }\end{array}$ & Cases & Treatment \\
\hline $\begin{array}{l}\text { Palpebral inflammatory } \\
\text { oedema }\end{array}$ & 15 & $\begin{array}{l}12 \text { conservative } \\
3 \text { conservative }+ \text { surgical }\end{array}$ \\
\hline Orbital cellulitis & 10 & $\begin{array}{l}\text { Surgery with intensive } \\
\text { antibiotherapy }\end{array}$ \\
\hline Subperiosteal abscess & 6 & $\begin{array}{l}\text { Surgery with intensive } \\
\text { antibiotherapy }\end{array}$ \\
\hline Orbital abscess & 3 & $\begin{array}{l}\text { Surgery with intensive } \\
\text { antibiotherapy }\end{array}$ \\
\hline $\begin{array}{l}\text { Cavernous sinus } \\
\text { thrombosis }\end{array}$ & 1 & $\begin{array}{l}\text { Surgery with intensive } \\
\text { antibiotherapy }\end{array}$ \\
\hline
\end{tabular}


ture becomes more difficult, blurring clinical aspects. As stated above, this study used Chandler's classification of orbital complications of sinusitis due to its simplicity, even though the classification was designed prior to computer imaging.

The most commonly occurring complication is palpebral inflammatory oedema, which Moloney referred to as preseptal cellulitis and reported it as being encountered more often in children; this was noted in our study too. The upper eyelid becomes swollen and hyperaemic due to a blockage of vein drainage from an ethmoidal sinusitis. Chemosis and proptosis are absent, both of which usually indicate postseptal infection. Vision remains unaffected and the eyeball moves in all directions. Usually, the oedema is most notable in the morning and persists throughout the day, with a slight reduction. When the oedema does not improve, it shows a postseptal inflammation inside the orbital cave. The appearance of proptosis indicates an advance of the orbital infection toward cellulitis. Proptosis, as well as chemosis, indicates the spread of an inflammatory process in the anterior of the orbit. The movements of the eyeball begin to become limited, and vision starts to weaken from the pressure on the optic nerve. Conservative treatment does not produce a fast reduction of the symptoms; therefore, surgical intervention is obligatory in these cases (Figure 1).

Another complication is subperiosteal abscess of the orbit, where an accumulation of pus forms between the bones
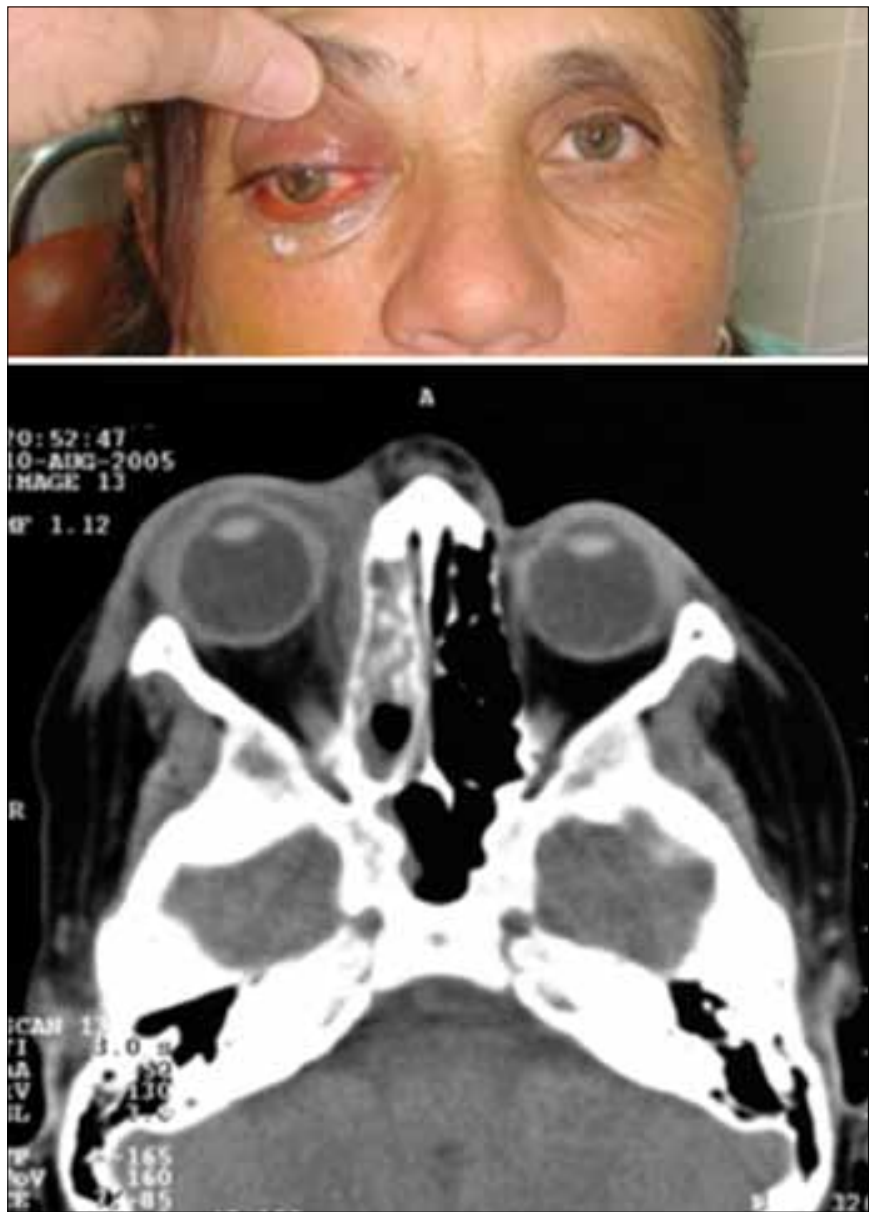

Figure 1. A patient with orbital cellulitis and the corresponding CT-Scan of the orbit and the periorbita, usually between the lamina papyracea and the periorbita. Proptosis, chemosis and limited movement of the eyeball are present, but the eyeball makes a lateral downward switch. Pain is experienced when the superior-medial corner of the orbit is touched. All cases in this series were in patients over the age of 20 , all of whom underwent surgical intervention under the protection of combined antibiotherapy.

When cases of orbital cellulitis do not receive appropriate treatment, the inflammatory oedema can progress towards a purulent inflammation. An accumulation of pus begins in the retroorbital adipose tissue. This is a more severe complication because it makes up the precedents for the septic thrombosis of the cavernous sinus, or the passing of the infection through nervous routs into the intracranial space. Besides the symptoms that were mentioned, exophthalmos, ophthalmoplegia and a weakening or loss of vision can also occur. The patient experiences constant pain and the affected eyeball is sensitive to touch. There were three such cases in our series, one of which was under the age of 20. Only one patient lost vision: he was treated in an ophthalmology outpatient clinic, and after a few days was admitted to the Otorhinolaryngology Department. When admitted to our care, the vision had already been lost. The starting point was an acute frontoethmoiditis.

Lastly, when bacterial infection is not stopped, or when treatment is delayed, the infection will follow the orbital veins toward the cavernous sinus. There was only one case with orbital complications involving bilateral oedemas of the eyelids, and there was a suspicion of septic thrombosis of the cavernous sinus. All of the sinuses of one side and the orbital abscess were opened up.

Despite the fact that we mainly relied on clinical and surgical exploration to determine these diagnoses, CT scans played an undisputable role in the determination of a topical diagnosis and the correct differentiation of such pathologies. Therefore, today, follow-ups are expected to be performed every hour via computer imaging in order to track the development of the pathology and to determine the appropriate time for intervention (11-13).

Today, there are discussions regarding endoscopic surgery of the sinuses as treatment for these complications (3-5, $13,14)$, but this does not seem the most appropriate in the presence of acute infection and haemorrhage that often accompany an intervention of this kind; however, it can always be kept under consideration. In our country, endoscopic surgery of the nose and paranasal sinuses is a new development, since 2005 in private clinics, but is never used in cases of orbital complication. Two cases in our series came from private clinics. However, this argument does not diminish the value of endoscopic interventions as the future of surgery of the nose and sinuses.

Young patients, especially children, respond better to conservative treatment. This is an observation in accordance with other observations (15), but our cases mainly presented with inflammatory palpebral oedema. In other cases of orbital complications where conservative treatments did not show major improvements to the symptoms in the first 24 hours, we moved forward with surgery. Other authors insist on conservative 
treatment in children, basing their point of reference for surgical intervention on contact with the optic nerve (16-19). These authors may be being reserved regarding surgery due to the classical idea of osteomyelitis intervening on an acute sinusitis (20-21). We believe that this idea is outdated and belongs to an era prior to the antibiotics; also, our interventions occurred under the protection of antibiotics. Also, reports from other authors have mentioned average stays in hospital, which were higher than the average reported in this series.

In conclusion, we concur that, despite their classification, orbital complications of sinusitis should be considered severe pathologies. They are life-threatening and also threaten the patient's quality of life. The appearance of oedema in the corner of the eye in a case with acute sinusitis should be recognised immediately and should be taken under serious consideration (22).

Complications of sinusitis, whether acute or chronic, appear to be severe morbidity, which may sometimes have a fatal outcome. Early diagnosis and aggressive treatment are key to the reduction of unwanted manifestations. Compared to previous decades, these conditions have been declining thanks to proper and timely communication, diagnostic methods, and the intervention of a series of updated antibiotics. The otorhinolaryngologists, ophthalmologists and general physicians should always be aware of symptoms that could indicate complications of sinusitis.

\section{Ethics Committee Approval: N/A.}

Informed Consent: Informed consent was obtained from patients who participated in this study.

Peer-review: Externally peer-reviewed.

Author contributions: Concept - P.R.; Design - P.R., D.V.; Supervision - D.V., J.D. Resource - P.R., J.D.; Materials - Department of ORL-Ophthalmology ; Data Collection\&/or Processing - M.X., J.D.; Analysis\&/ or Interpretation - P.R., D.V.; Literature Search - P.R.; Writing - P.R.; Critical Reviews - P.R.

Conflict of Interest: No conflict of interest was declared by the authors.

Financial Disclosure: No financial disclosure was declared by the authors.

\section{References}

1. Stankiewicz JA, Nevell DJ, Park AH. Complications of inflamatory disease of the sinuses. Otolaryngol Clin North Am 1993;26: 639-55.

2. Gardiner LJ. Complicated frontal sinusitis:evaluation and management. Otolaryngol Head Neck Surg 1986;95:333-43.
3. Ali A, Kurien M, Matheus SS, Mathew J. Complications of acute infective rhinosinusitis:experience from a developing country. Singapore Med J 2005;46:540-4.

4. Suhaili DN, Goh BS, Gendeh BS. A ten year retrospective review of orbital complications secondary to acute sinusitis in children. Med J Malaysia 2010;65:49-52.

5. Siedek V, Kremer A, Betz CS, Tschiesner U, Berghaus A, Leunig A. Management of orbital complications due to rhinosinusitis. Eur Arch Otorhinolaryngol 2010;267:1881-6. [CrossRef]

6. Chandler JR, Langenbrunner DJ, Stevens ER. The pathogenesis of of orbital complications in acute sinusitis. Laryngoscope 1970;80:1414-28. [CrossRef]

7. Moloney JR, Badham NJ, McRae A. The acute orbit preseptal (periorbital) cellulitis, subperiosteal abscess and orbital cellulitis due to sinusitis. J Laryngol Otol 1987;101(Suppl.12):1-14.

8. Mortimore S, Wormald PJ. The Groote Schuur hospital classification of the orbital complications of sinusitis. J Laryngol Otol 1997;111:719-23. [CrossRef]

9. Spires JR, Smith RJ. Bacterial infections of the orbital and periorbital soft-tissues in children. Laryngoscope 1986;96:763-8. [CrossRef]

10. Fearon B, Edmonds B, Bird R. Orbital-facial complications of sinusitis in children. Laryngoscope 1979;89:947-53. [CrossRef]

11. Bolinaga U, Perez N, Lobato R, Martinez-Seijas P, Sumitier Perez E. Abscess of the orbit as a complication of acute sinusitis:double surgical approach. Eur Arch of Otorhinolaryngol 2009;266(A368):1037-8.

12. Stankiewicz JA, Park AA, Newell DJ. Complications of sinusitis. Curr Opin Otolaryngol 1996;4:17-20. [CrossRef]

13. El-Silimi O. The place of endonasal endoscopy in the treatment of orbital cellulitis. Rhinology 1995;33:93-6.

14. Manning SC. Endoscopic management of medial subperiostal orbital abscess. Arch Otolaryngol Head Neck Surg 1993;119:789-91. [CrossRef]

15. Brown CL, Graham SM, Griffin MC, Smith RJ, Carter KD, Nerad $\mathrm{JA}$, et al. Pediatric medial subperiosteal orbital abscess:medical management where possible. Amer J Rhinol 2004;18:321-7.

16. Durand ML. Intravenous antibiotics in sinusitis. Curr Opin in Otolaryngol 1999;7:7-10. [CrossRef]

17. Poole MD. Antimicrobial therapy for sinusitis. Otolaryngol Clin North Am 1997;30:331-9.

18. Singh B. The management of sinogenic orbital complications. J Laryngol Otol 1995;109:300-3. [CrossRef]

19. Nageswaran $S$, Woods CR, Benjamin DK Jr, Givner LB, Shetty AK. Orbital cellulitis in children. Pediatr Infect Dis J 2006;25:695-9. [CrossRef]

20. Ryan JT, Preciado DA, Bauman N, Pena M, Bose S, Zalzal GH, et al. Management of pediatric orbital cellulitis in patients with radiografic findings of subperiosteal abscess. Otolaryngol Head Neck Surg 2009;140:907-11. [CrossRef]

21. Oxford LE, McClay J. Medical and surgical management of subperiosteal orbital abscess secondary to acute sinusitis in children. Int J Pediatr Otorhinolaryngol 2006;70:1853-61. [CrossRef]

22. Radovani $P$, Xhumbi K, Golemi H. Ënjtjet e përsëritura rreth orbitës. Revista Mjeksore 1989;6:49-52. 